\title{
Research on the Integration Development of Digital Art Education in the New Media Environment
}

\author{
Zhou Yuanyuan ${ }^{1, a}$
}

1. Chongqing College of Electronic Engineering, Chongqing, China

2.459611127@qq.com

\begin{abstract}
Keywords: Integration Development, Digital Art Education, New Media Environment
\end{abstract}
\begin{abstract}
With the rapid development of the Internet, new media environment has become more sophisticated, in this context, and fresh vitality, driven by digital art based on the new media environment becomes the current hot name. Various colleges and universities have also set up various courses under the direction of digital art. Through the development of a few years, digital art has become the focus of various art schools construction subjects. This paper takes modular curriculum design, the creation of the actual project and multi-concept learning environment management system, and achieved good teaching effect, more and more schools and employers industry recognition.
\end{abstract}

\section{Introduction}

Digital media arts education beginning with the establishment of the overseas part art institutions and engineering colleges in the mid-1990s, at home and abroad over the past decade has become a prairie fire. "New media" created "new thinking" and "new art" has become the Art Education Reform fuse. The digital age media is to promote change in the mode of transmission, resulting in a variety of digital, including digital printing, digital imaging, online media and mobile media and other forms of media. This change to the modern design education also brings a great promotion, making science and art, media and design, among the media in the form of interdisciplinary and integrated education innovation, digital media, appeared to break the traditional division of disciplines such as "technical art" movies, animation, TV, DV, Internet and streaming media for the first time a unified form of technical and visual art language.

Digital Media Arts has dual characteristics of engineering and art, as of 2007, the Ministry of Education for approval or acceptance of the request for the record of digital media art (080623W) over 30 professional colleges and universities, including both engineering colleges, teacher colleges have arts institutions which can be granted to both professional engineering degree to be awarded a degree in literature. This fully embodies the "combination of art and engineering," the subject of professional features. Therefore, there will be combined with digital technology, digital media, visual arts and culture of the three designated as digital media art is a logical induction. In 2006, China proposed the establishment of a new concept of "innovative country", under the guidance of the concept of such a macro, follow the social demand for digital media art and design talent, Chinese design art education ushered in a new development. Creative introduced the concept of Art and design, College of Digital Arts came into being. Data show that: At present over 80\% of colleges and universities have set up art majors, and animate professional class has more than 230 . We can say that the media associated with the creative industry has become one of the professional art education in China is currently the most popular. While expanding the size of school, but on the basic theory of digital media art research, important questions Curriculum and Training Programs, are still not well resolved.

From the international academic and educational setting for "digital media art," the subject matter of point of view, mainly related to the disciplines of visual arts, art and design, information dissemination, human-machine interface, multimedia, network, animation, games, virtual reality is concerned, the main range of available "digital media art and design," summed up, covering the scope of science in the 21st century digital design. As digital technology continues to penetrate to 
the art and design, art education and professional division of foreign universities in recent years has shown more and more "integrated" development trend. Prof. Dr. Institute of Art and Communication of Beijing Normal Xiaoyong Liang said: "The United States, a total of more than 3,000 universities, of which there are about 1003 schools have similar professional inside, namely digital media, creative media, digital art is characterized by its discipline: Digital , interactive, three-dimensional, multimedia; layout disciplines including centralized and decentralized; degree distribution including arts, science, engineering disciplines; teaching both the level of training, college and university education, but also a higher level of graduate education "

In recent years, a number of well-known foreign universities and art and design institutions such as Yale University, New York School of visual Arts, MIT, Michigan State University, University of California, also have media research design, multimedia design, visual computing performance, dynamic form of expression , Lingo language, Java language or language, media expansion design, audio design, web design, video design, virtual reality design, digital media and software technology into teaching areas. Wherein digital media theory courses include: Digital Media Arts Studies, digital media and science, digital media art history, new media research, media project design and management, interactive media design principles, the numbers game and society, audio-visual product design and game design Wait. We can see that foreign digital media arts education more concerned with the nature and forms of digital media art, especially in the disciplines involved in digital technology, interactive technology, media sociology and media design and other topics will be integrated focus strongly reflects the art design and digital technology features. Thus, digital media arts education in foreign countries has formed a relatively complete system of discipline. Especially in terms of discipline theory and school of thought, which is the digital media arts education domestic colleges and universities have a demonstration and reference.

\section{The Concept of Digital Art}

The 21st century, the rapid development of modern science and technology, this new digital art, is gradual deepening of our lives, and aroused widespread concern and attention. The formation of a new art form independent aesthetic value of works of art after Broadly speaking, digital art refers to the use of digital technology and information technology, image, video, text, and voice to be digitized and integrated design and use of, it is interactive and online media to use the basic features, including online games, computer illustration, video effects, digital imaging, virtual reality, digital music. Can also say that all computer technology produced by the media culture can be attributed to the category of digital art, digital art computer technology, the need to involve the knowledge of culture, art and design, computer and information technology and other fields.

\section{The Situation Analysis of Digital Arts Education}

Since the time of the digital arts industry is short, digital art education started much later, at present, professional teachers domestic digital arts education knowledge and ability structure is irrational, the majority of professional teachers undergraduate computer science or art and design college graduate teachers generally young age structure, a truly digital art production experienced and highly educated teachers teaching experience very few, less high-end talent. Even the existence of "Art plus digital art computer equals", "ability to master computer software equivalent to master digital art capabilities" and other misconceptions, there has been artistically understand computer technology, understand digital technology is often based on a lack of artistic phenomenon, and Engineering Colleges simply focus on digital technology, art schools focus only on the drawbacks of artistic creation ability has emerged, leading to widespread trained personnel strong theoretical, practical difference, enterprises cannot meet the job requirements. Moreover, the new digital arts colleges do most professional academic foundation is weak, low level of technical skills, talent training mode backward, which are seriously affected the quality of teaching and teaching effectiveness, inevitably leads to the disconnect between teaching and demand make digital arts 
education is difficult to adapt to changes in demand brought about by industrial restructuring, therefore, the current industry professionals needed digital art is a big gap, survey data showed on film and television animation direction, the talent gap in 2008 was 80 million. This has become a bottleneck restricting the development of the digital art industry, but also makes the operating costs of digital art business remain high, reducing the competitiveness of enterprises, which are restricting technological development and hinder an important factor in industrial progress. Therefore, cultivating digital art professionals, the development of digital art education has become a problem of government, industry associations, enterprises and the community is very concerned about.

Effect of computer art in that it not only more efficient creation, but also to art and design has brought new styles and forms of artistic expression has become increasingly diverse. Development of digital media technology, comprehensive application of a variety of ways to communicate, visual arts innovation provides new conditions and opportunities, the new hot spot emerging. Comprehensive means application video, animation, interactivity and other works of art created to enrich the arts, and gradually evolved into a new field. Internet facilitates the transmission of information, to provide people with a new media to communicate, but also created a new form of communication. Artists can cross-regional co-creation on the Internet, the creation and appreciation of art is no longer subject to geographical constraints. Art is the process of innovation and integration of computer technology, artificial intelligence is even possible to make art on their own according to the set criteria.

\section{The Policy of Digital Art Educational Integration Development in the New Media Environment}

Increase the Practical Courses to Enhance Students' Practical Ability. Theory Courses typically include general culture lessons, specialized basic courses, specialized courses; practical courses include experiments, practice, training courses. Objective is the foundation of theoretical study humanities, master of professional theory and technical knowledge; practical lesson is to cultivate professional competence, acquisition of practical skills. Two types of courses roles and complement each other, work together to train highly skilled professionals and services. General shortage of teaching practice, causing students to master the theoretical knowledge is good, but the ability to create relatively poor. To change this situation, we have to promote quality education as the goal, to strengthen the practice of curriculum development, the formation of a new system of practical courses include practice curriculum system, teaching content, teaching methods, teaching methods and teaching institution, including the.

Strengthen the consolidation of good practice in the course of basic education curriculum at the same time. Practice may be the actual course of the project company may also be a virtual reality project company. Take art and design course, if theory and classroom practice speaking combining ignore actual integration projects and programs, I want to learn it is dull. Today's students' desire for knowledge is limitless, as can be interspersed in the finish after some theoretical courses able to understand the theory of thematic curriculum development project will enhance students' interest in learning. Experience the fun of learning, and fun in the learning experience.

Innovative Curriculum System Reform and Build Multi-Mode Dynamic Teaching Modules. The basic idea of the curriculum system reform are: Reform of professional-based, teacher-centered curriculum design and training links, with the transition to a comprehensive knowledge-based, learner-centered curriculum design and training sectors; Construction "2 +2 "curriculum modules, highlighting the students' knowledge, ability, quality structure of the optimal combination. The so-called "2 + 2" mode refers to the four-year bachelor's incubation period is divided into two sections, the first two school years by professional art education Scope of basic education and professional foundation courses. After two years of professional education and practice to enhance the curriculum, according to the principles of both quality education and professional education, according to the " $2+2$ " comprehensive training mode, curriculum system in order to "carry out the former two year basic education and professional Elementary Education to enhance student literacy, 
high school implement distinctive professional education to enhance students' innovative spirit and practical ability "as the main criterion, to build an integrated university system.

In the curriculum, compared to traditional training programs, in the first semester of freshman courses introduced, the purpose is to enable students to establish clear learning objective, the correct values, a positive attitude and good team spirit and so on. Secondly, in the third year university semester addition of a "career planning" course, in the form of lectures employ both psychological theory literacy, and rich professional experience of the type of professional people majors career planning and guidance. To enable students to fully understand themselves, their own internal conditions (such as: interests, strengths, ways of thinking, etc.) adequate analysis and judgment. Juniors and seniors two years of virtual projects and actual projects as the way to achieve social integration and the purpose of that is out of school have work experience projects for them to find work to lay a solid foundation.

Focus on the Students Artistic Creativity to Meet Market Demand. Characteristics of digital art across art, technology, both areas calls for the training of personnel but also to achieve the combination of art and technology, taking into account the original ladder train personnel and low-end talents. The main problems in the domestic digital design companies recruit talent when encountered was difficult to communicate between artistic talent and technical personnel, understand the art of non-technical and skilled do not understand the arts. Some experts say that one of the main reasons for this situation is that the relevant Chinese universities and other educational establishments of the market sensitivity and adaptability to poor, yet professional setting and adjustment to keep pace with the needs of industrial development; the other, in the conventional division discipline seriously, digital arts professionals and the starting point for efforts to train enough.

\section{Conclusion}

Today, the information age is built on the computer as a platform foundation. Visual arts and visual arts education is all about. In the near future, with the computer as a platform for digital art will become the mainstream of the visual arts, digital content and cultural industries will become a growth point of China's economic development. Thus, China's digital art education should seize the opportunity to grasp the mainstream of the times, timely adjustment of teaching system and discipline construction, establishment and development of the 21st century digital art education, promoting the development of Chinese digital arts education.

\section{References}

[1] Huifang Zhou: China Educational Technology, Vol. 6 (2014) No 53, p.25-26

[2] Hongli Zhang: Art Reviews, Vol. 12 (2012) No 27, p.74-76

[3] Qin Guo: World History of Modern Design, Vol. 1 (2013) No 33, p.11-14

[4] Jieming Liu: Guangxi Normal University, Vol. 3 (2007) No33, p.121-124

[5] Meng Wei: Chinese Philosophy of Art, Vol. 10 (2013) No 33, p.58-61 